\title{
Publishing opportunities of doctoral candidates
}

\author{
Kvetoslava Rešetová
}

Slovak University of Technology in Bratislava, Faculty of Materials Science and Technology Trnava, Paulínska Trnava, Slovakia

\section{Email address:}

kvetoslava.resetova@stuba.sk

\section{To cite this article:}

Kvetoslava Rešetová. Publishing Opportunities of Doctoral Candidates. Science Journal of Education. Vol. 1, No. 5, 2013 , pp. 90-96. doi: $10.11648 /$ j.sjedu.20130105.16

\begin{abstract}
Publication activities of $\mathrm{PhD}$ candidates as a result of an independent creative exploration and research are becoming an important part of the publication outputs of the University. Seeking opportunities for publishing results of scientific research of young researchers is becoming a priority task of information management. Publishing papers in journals and proceedings of top international quality is the criterion for the University quality evaluation. Current academic milieu requires searching for new methods of using information and organisation of informational structures which are reflected into its new services and products.
\end{abstract}

Keywords: PhD Candidates, Publication Activities of PhD Candidates, Opportunities for Publishing, Top Quality Publication Environment, Knowledge Management

\section{Introduction}

Doctoral study programmes focus on the acquisition of knowledge based on the current state of scientific knowledge and the students' particular contribution, which is the result of scientific research and independent creative activity in the field of science or technology, or individual creative activities in the arts. Graduates of the doctoral programme receive university education of the third degree [1]. Universities can carry out doctoral courses in cooperation with accredited external training institutions (e.g. accredited institutes of the Slovak Academy of Science). Doctoral studies consist of educational and scientific parts. Postgraduates must be prepared for an independent and creative work in the field of research and development, or independent theoretical and creative artistic activity.

According to Article 84, Section 5 of Act No. 131/2002 Coll. on universities, on amendments and supplements to certain laws as amended and upon the declaration of the Accreditation Commission, the Minister of Education of the Slovak Republic has conferred a right to the Faculty of Materials Science and Technology in Trnava, Slovak University of Technology in Bratislava (MTF STU), Slovakia to grant relevant academic titles to graduates of doctoral study programmes in the following branches [3]:

Materials Engineering, Processing and Application of Non-Metals, Machine Technologies and Materials, Production Devices and Systems, Industrial Management,
Engineering of Production Quality, and Integrated Safety .

One of the essential criteria for the evaluation of the University are its publication activities. In the process of complex accreditation of universities, the publication outputs are evaluated in attribute of Environment. The cope and outcomes of doctoral studies are evaluated as first sub-criterion. Editorial outputs of doctoral candidates, which are a co-part of this sub-criteria, are divided into outputs Category A (top international quality), B (internationally recognized quality), $\mathrm{C}$ (nationally recognized quality), D (others). The inclusion of outputs into different quality levels is made on the basis of specific criteria that apply to the relevant area of research. This means that each area of research has its rules valid for inclusion of outputs to categories of quality, A, B, C and D [4].

\section{Theoretical Framework}

Needs analysis will create tools to transfer knowledge in the academic area. The base of analysis will be the fact that information is an important factor of efficiency of each contemporary university. The needs determine the level, attractiveness, and quality of its education process and simultaneously they are a condition and output of quality research activity of a research university. Research and education represent the most efficient investments into development of production factors which can be evaluated in two forms. Firstly, they support innovation and improve 
efficiency of the formation process of values in education and research organizations. Second, they create conditions for organizational self-development. The advantage and efficiency of knowledge management must be proven by the amount and quality of outputs. Quality university education will always need a quality information system for the education and research process.

A basic definition of these efforts relates to a revision of knowledge's position in the value hierarchy of knowledge. Knowledge should be understood as a universal advantage which simplifies support systems of research. Knowledge management can be understood as a process which supports and enables integrated access and application of all information activities and sources in research phases. The quality of an organization's knowledge potential and the intensity of its development are closely connected with information management. The advantage and efficiency of knowledge management must be proven by the amount and quality of outputs. The quality of university education will always need a quality information system for the education and research process. When we understand knowledge management as a part of information management with the function defined as rational creation and application of information, and as an organization of information structures, then this is proof that implementation of knowledge management is a result of practical and theoretical change of service paradigm in the academic area.

\section{Publishing Rules for Doctoral Candidates}

The scientific part of doctoral studies includes the research of the current scientific problem in the field. The scientific part is carried out within the subject "Dissertation Project I - VI" (with a total capitation of 100 credits) and in the subject "Research Work" (with a total capitation of 40 credits).

Allocation of points for publication outputs of doctoral activities:

Table 1. Internal evaluation of publication outputs of doctoral candidates

\begin{tabular}{lll}
\hline Category & Category characteristics & Points \\
\hline A category & top international quality & 30 points \\
B category & $\begin{array}{l}\text { internationally recognized } \\
\text { quality }\end{array}$ & 20 points \\
C category & nationally recognized quality & 10 points \\
D category & others & 1 point \\
\hline
\end{tabular}

Table 2.Conversion of points to credits for subject "Research work"

\begin{tabular}{ll}
\hline Number of achieved points & Value of achieved points in credits \\
\hline $1-2$ points & 1 credit \\
$3-4$ points & 2 credits \\
$\ldots \ldots$ & 14 credits \\
$27-28$ points & 15 credits \\
29 and more points & \\
\hline
\end{tabular}

Conditions of publishing are defined by publishing rules for doctoral candidates, e.g. publishing research results in agreement with the principal investigator of research, with the approval of the supervisor and the like. For permission to defend dissertation thesis, doctoral candidate must meet the requirements to achieve a minimum of 3 publications in category B (internationally recognized quality), or 1 publications in category A (top international quality).

\subsection{Statistics of Publication Outputs of Full-Time PhD Candidates}

Publication outputs of doctoral candidates with the Faculty affiliation are becoming a subject of compliance with the criteria of evaluation of the Faculty scientific research activities for funding purposes (i.e. faculty financial grant from the state budget), for the purpose to follow their qualification growth, and for the faculty accreditation purposes (categorisation of the Faculty in the highest category - Research Faculty of the Research University).

Table 3. Number of (full-time) doctoral candidates at MTF STU

\begin{tabular}{cc}
\hline Academic year & Full-time PhD candidates \\
\hline $2006 / 2007$ & 7 \\
$2007 / 2008$ & 8 \\
$2008 / 2009$ & 19 \\
$2009 / 2010$ & 17 \\
$2010 / 2011$ & 36 \\
$2011 / 2012$ & 44 \\
$2012 / 2013$ & 69 \\
\hline
\end{tabular}

Notice: The number of full-time $\mathrm{PhD}$ students depends on the financial policy of the Ministry of Education, Science, Research and Sport of the Slovak Republic.

Evidence of publications (at the Faculty guaranteed by the Academic Library) gives the opportunity to get an overview of the publication outputs of $\mathrm{PhD}$ candidates for two areas of evaluation:

- qualification growth of $\mathrm{PhD}$ candidates (achieving evaluation criteria before defending the thesis),

- evaluation of the Faculty for the purposes of accreditation. 
Table 4. Number of publication outputs of full-time PhD candidates for the purpose of grant from the State budget

\begin{tabular}{|c|c|c|c|c|c|c|}
\hline Selected categories of publication outputs for the purpose of grant from the state budget & $\begin{array}{l}\text { Year } \\
2007\end{array}$ & 2008 & 2009 & 2010 & 2011 & 2012 \\
\hline University textbooks published in national publishing houses & & & & & 1 & 1 \\
\hline Scientific monographs published in national publishing houses & 1 & & 1 & & & \\
\hline Chapters in scientific monographs published in national publishing houses & 1 & & & & & 1 \\
\hline Scientific papers in foreign journals indexed by Current Content & 1 & 3 & 3 & & 4 & 2 \\
\hline Scientific papers in national journals indexed by Current Content & 1 & & & 1 & 1 & 1 \\
\hline Scientific papers in other foreign journals than indexed by Current Content & 3 & 1 & 3 & 21 & 28 & 48 \\
\hline Scientific papers in other national journals than indexed by Current Content & 10 & 3 & 7 & 42 & 34 & 41 \\
\hline Scientific papers in peer-reviewed foreign proceedings and monographs published abroad & & 2 & 7 & 17 & 9 & \\
\hline Scientific papers in national peer-reviewed proceedings and monographs & & 7 & 4 & 5 & 8 & 3 \\
\hline Papers published in foreign scientific conference proceedings & 9 & 12 & 16 & 96 & 185 & 176 \\
\hline Papers published in national scientific conference proceedings & 38 & 21 & 70 & 92 & 117 & 106 \\
\hline Abstracts of conference papers published abroad & & & & 2 & 12 & 4 \\
\hline Abstracts of papers from national conferences & 1 & 1 & 1 & 3 & 4 & 6 \\
\hline University textbooks and teaching texts & 1 & 3 & 1 & & 2 & 3 \\
\hline Total with other categories of publication outputs & 76 & 64 & 126 & 324 & 432 & 474 \\
\hline
\end{tabular}

Notice: PhD candidates are authors or co-authors of publications

For evaluation of publication activities of $\mathrm{PhD}$ candidates, publications that are registered in Web of Science, Scopus and IEEE databases (defined by the Accreditation Commission) have the highest credit rating (i.e. inclusion of publications in output category of top international quality - category A).

Table 5. Number of publications of doctoral candidates in monitored databases for category $A$

\begin{tabular}{ccccc}
\hline & & \multicolumn{3}{c}{ Databases } \\
\cline { 3 - 5 } Year & $\begin{array}{c}\text { Number of } \\
\text { records }\end{array}$ & $\begin{array}{r}\text { Web of } \\
\text { science }\end{array}$ & Scopus & IEEE \\
\hline 2007 & 76 & 2 & 2 & 0 \\
2008 & 64 & 8 & 3 & 0 \\
2009 & 126 & 8 & 4 & 1 \\
2010 & 324 & 4 & 4 & 1 \\
2011 & 432 & 15 & 12 & 1 \\
2012 & 474 & 21 & 37 & 4 \\
\hline
\end{tabular}

Scholar status might affect the relationship between manuscript quality and journal quality in different ways throughout the publication process. One way is at the front end of the publication process, particularly when a scholar is determining where to send a manuscript for publication consideration. Status might inherently affect a scholar's decision about where to send a manuscript. For example, scholars with lower status may not target journals with higher impact factors simply because these scholars may not be confident in going under competitive review. Despite producing manuscript of high quality, low status scholars might not consider sending manuscript out for review in journals with higher impact factors as readily as would a higher status scholar [2].

\subsection{Support and Publishing Opportunities of Doctoral Candidates}

The aim of publishing activities of the Faculty is to provide rapid transfer of the development of scientific knowledge into curricular content and thus facilitate students' access to new knowledge, to improve educational process and support research and scientific environment through publications. The Faculty applies the unconditional compliance with the Act No. 618/2003 of 4th December 2003 on Copyright and Rights Related to Copyright (Copyright Act), and moral and ethical principles when publishing to the exclusion of any possible forms of plagiarism for all issued publications.

Searching for space (especially foreign) for publishing the research results of young scientists is quite complex and demanding task. On the one hand, it is essential that candidates reported the results of their own creative work. On the other hand, publishing the papers in the top credit rating categories is quite a challenging process. Moreover, this fact is determined also by number of journals / proceedings that are registered in various databases from the areas of the faculty research.

By providing the criteria to achieve publication outputs of doctoral candidates, the Faculty management established conditions for the publication support. They are not only internal resources and support mechanisms for publishing, but especially financial support of the Faculty institutes to achieve the outputs of top quality (payment of registration fee for events, the proceedings of which are indexed in the 
monitored databases; fee for publication in top journals, etc.). Motivating factor provided by the Faculty management are the above-tariff earnings for the outputs of international top quality.

Opportunities of the doctoral candidates to publish their own research results at the Faculty:

\subsection{Electronic Textbooks}

The present educational process and scientific research in universities is characterized by a process of penetration of information and communication technologies. On the one hand, electronic publishing creates a space for rapid transfer of knowledge from these areas of academic life (in particular) to its core customer base - i.e. to students. On the other hand, the implementation of electronic publications in the academic environment represents a set of various problems and pitfalls. Since 2005, the Faculty has been implementing a project for publishing electronic textbooks through its own publishing house. Success of the entire project was conditioned not only by the activity of all involved parties (i.e. the Faculty management, Academic Library and the Centre of Computer and Information Technology), but particularly by the satisfaction of its users - students. This project emerges from the expansion of services provided by the Academic Library in the overall concept of the Slovak University of Technology in the area of developing a virtual library on the Internet by using web services. This is a conceptual solution to the problem of eliminating the unavailability of academic literature. The statute of the publishing activities allows also authors of textbooks with an academic title PhD.

\subsection{Monographs on the Basis of Qualification Theses}

Dissertation theses of doctoral degree students are independent scientific outputs assessed in the process of the Faculty evaluation within different criteria than publication outputs. In order to appreciate the scientific approach and the research results published in the defended dissertation theses, the University decided to publish scientific monographs based on qualification theses. Procedural requirements must fulfil the conditions and processes of the issuance of such a monograph. The core prerequisite for publishing qualification output in a form of monograph is to meet the requirements under Directive of Ministry of Education, according to which:

a) scientific monographs are considered the original monothematic scientific works of at least three author's sheets (60 pages),

b) scientific monograph must be peer-reviewed before its publication by at least two experts, whose names are listed in the monograph,

c) the monograph must have an ISBN number.

The fact whether the qualification work satisfy formal requirements for being issued as a monograph is considered by the evaluation commission established for the purpose of the qualification work defense.

\subsection{Editions of Monographs at Foreign Partners}

Although the University has created the conditions for the transfer of qualification works into monographs, it is determined by the national environment (i.e. scientific monographs published in national publishing houses). Besides the articles in registered databases, scientific monographs published by a foreign publisher have the highest credit rating in the evaluation of publications. To get the possibility of publication abroad is not easy for lifetime research outputs of older scientists, much less so for beginning young scientists. One of the opportunities the Faculty has utilised, are bilateral agreements on cooperation between the Faculty and foreign partners, who have issued a special edition of monographs of authors from MTF STU in their institutions (e.g. HZDR Dresden, IFW Dresden, TU Ilmenau, FH Anhalt). All monographs must meet the basic criteria for a monograph both at home and abroad. Since 2007 (until 2012) the Faculty managed to publish 47 scientific monographs issued by a foreign publisher. Seeking opportunities of issuing monographs in foreign publishing houses (extending the circle of publishers) is a permanent task, which is the priority interest of the Faculty.

\subsection{Custom Publishing}

In 2012, the Faculty adopted a program to expand opportunities for publishing activities of MTF STU abroad through participation in the Custom Publishing Programme. The publishing activities are focused on:

- primarily, issuing university textbooks in foreign publishing houses Pearson and Cengage,

- possibility of issuing publications in the form of monographs (Cengage Publishing House).

"Custom Publishing Programme" makes a space for the emergence of university textbooks in English and American productions. These shall include possibility of joint authorship of publications with foreign authors (complementary university textbook), or the possibility of an independent scientific work of the author from MTF STU. Effects of participation in the Custom Publishing Programme:

- new publishing area for MTF STU in renowned foreign publishers,

- $\quad$ strengthening of category "university textbooks published in foreign publishing houses",

- co-authorship with foreign partners,

- $\quad$ predicting the occurrence of other university textbooks by using parts of the work of the author from MTF STU, it means new publications of the authors from the Faculty,

- $\quad$ possibility of an increased citation index of the authors from MTF STU,

- $\quad$ knowledge transfer and the rapid transfer of scientific knowledge into the curricular content,

- facilitating students' access to new knowledge, improving the educational process, 
- provision of academic literature for students in the English language,

- $\quad$ international credibility of the Faculty teaching and research staff,

- $\quad$ presentation of works by authors from MTF STU in e-book collections of publishers,

- $\quad$ significant presentation area for the Faculty public relations.

\subsection{Faculty Journals}

The Faculty publishes two magazines - Research papers of the MTF STU and the Internet journal Materials Science and Technology. Both magazines are published in the English language. They are focused on the Faculty research fields - materials engineering, metallurgical and mining sciences, mechanical engineering (machine technologies), computer science, automation and telecommunications, and environmental engineering. Both journals provide double-blind review, which guarantees:

- impartial reviews of the quality of published outputs,

- confirmation of established knowledge of the current state of the issue in domestic and foreign literature, the systematic analysis and synthesis,

- $\quad$ explication of the used evaluation criteria in the paper,

- originality of the authors contribution to fundamental issues of theory, methodology and innovations, incentives for new research orientation,

- clear characteristics of the used procedures, especially in the application of statistical and empirical data,

- contribution to the knowledge of the current state, knowledge transfer and the development in the field,

- $\quad$ excluded possibility of reviewer's bias against the author,

- $\quad$ increased rate of fair judgment and evaluation of benefits of contributions.

The priority of the Faculty is registration of the journals in the monitored databases (WoS, Scopus, and so on). The main instrument to support the acquisition of the Impact Factor for the journals is electronic publishing through MetaPress technology that provides increased awareness of the journal, an interest in publishing, citing strategy thanks to AIS (automatic indexing of published papers) and making active links to the cited works. By serving metadata in abstracting and indexing services, as well as full-text databases, issuing and registration of DOI codes (Digital Object Identifier) for each published paper is one of the steps to register the journals in databases required in terms of accreditation.

\subsection{Presentations of the PhD Students}

A complex preparation of $\mathrm{PhD}$ students for independent research, including also presentation of partial results for gaining communication skills and other reasons. $\mathrm{PhD}$ students publish their outputs as a part of proceedings during the faculty events:

- International doctoral seminar - offers a platform for doctoral and research students at different stages of their studies, to present their ideas, problems and issues in an academically rigorous but supportive environment. Students will gain useful insights into methodological, theoretical, conceptual, and policy developments in the field as explored by other students. Throughout the day, different aspects of undertaking a doctorate will be discussed, from developing the research topic, to fieldwork and methodological issues. The Doctoral Seminar also offers a great opportunity for doctoral students to increase research and professional contacts.

- Student Research Conference - besides study, the students can be involved in the institutional research activity either by participating in research projects and the Student Research Conference, or working as research student-helpers. The Student Research Conference provides the bachelor's and master's students with a chance to get acquainted with research methods, to analyse a research task and articulate the attained research results in both oral and written forms, and to defend their opinion in a professional forum.

\subsection{Portal of Publishing at MTF STU}

Not only the legislative framework of doctoral studies, but especially the very nature of the studies themselves are shaping obligation to the publication activities. It is therefore appropriate that each doctoral candidate should adopt certain rules and principles of publishing, which will be followed in an independent creative activity. As with any other creative activity, also in publications, a kind of unified form or unified working procedure cannot be enforced. However, there are certain general principles that should be respected.

If the PhD candidate overcomes the first moment of the fear of the blank paper, to which s/he has to write something clear and logically arranged, the following rules should be borne in mind:

- the output presents yet unresolved problem, or a part of the problem, which concerns the author's dissertation,

- $\quad$ it is recommended to consult it with supervisor,

- $\quad$ selection of a quality source that also meets the criteria for inclusion of publications and the possibility of obtaining credits during the studies is necessary,

- $\quad$ there should be compliance with the formal characters for text editing,

- compliance with the rules of proper citation of the used sources is a must.

To overcome any confusion of the author in correct structuring of the text, to comply with applicable international standards in writing publications, the Faculty developed the Portal of publishing (updated regularly), which focuses authors in compliance with the rules when editing text, the rules of proper citation of sources and helps them to avoid the formal shortcomings in the development and creation of individual publication outputs. The fact that this portal has become the second most visited portal of its 
kind in the virtual environment proves that it is an effective support.

\section{Methodology}

Processes of correct classification of publication of $\mathrm{PhD}$ students require creation of system mechanisms:

- knowledge of publication value for evaluation processes

- access to electronic information sources of $\mathrm{PhD}$ students research

- $\quad$ support services of academic departments

- $\quad$ an efficient system for evidence of publication activity.

Methodology of evidence and processing of publication activity of $\mathrm{PhD}$ students defines the ways how to process by evaluation of output. It is important to select a relevant set of solution methods and a rational process of classification of publication activity into concrete categories to follow the defined aims. In accordance with a predicted process of problem solution a portfolio of methods can be defined:

- the general part of the classification method of publication activity applies methods of induction and deduction - induction as a process from general to concrete (this method is used in summarizing all evaluation parameters, where a subject of evaluation is publication activity); deduction as a method of observing, which determines priorities of outputs in defined conditions;

- $\quad$ an analytical part uses the methods of causal analysis the method of recovering of causal relation phenomena, which means the form of interactivity between processes, issues, systems and others (evaluation of output environment); methods of comparison comparison methods present basic research methods, their importance is based in data division into various files with the aim of their comparison and finding they present a base for generalisation of analysis outputs; index method - the method for distinguishing categories to particular importance, it means indices are added to concrete publications;

- $\quad$ evaluation processes use methods of calculation, their result is a determination of publication value for various evaluation purposes; methods of trend extrapolation extrapolation as a process of evaluation, classification (or selecting) of values, they formulate trends of the next development of particular problematic, an alignment of publication activities and others; bibliometric methods such as specific library-information methods enabling practical application in decision processes by management of science and research with application in the field, for example a measurement of scientific productivity of authors.

A mechanism of method selection for evaluation processes is determined from the type of evaluation and the character of criteria, while a combination of more methods is expected to be used in concrete steps of classification process of publication.

\section{The Importance of Evaluation and Monitoring of Publications in the Academic Environment}

Evaluation of publications as one of the most notable and most visible outcomes of creative works of the Faculty staff is one of objective tools for comprehensive evaluation of the Faculty. Of course, the Faculty comprehensive evaluation includes further criteria and its mechanism is very complicated. To measure the benefits of publishing activities, there is the possibility of using bibliometric outputs of information management of the academic library in assessing the impact of publications on the raising finance, as a precisely measurable and assessable output of the Faculty. The bibliometric methods, as specific library and information methods, allow practical use in decision-making in the management of science and research.

Financial cost on development and operation of the University can be quite accurately estimated, but the resulting effects are difficult to measure. For example, while marketing information system is measurable by increased financial income from the sale, in the field of science, research and education, the effects are reflected only indirectly and not immediately. In higher education institutions, the cost-benefit ratio is not (and cannot be) the main criteria. However, the issue of efficiency should not be neglected.

The University must continually fulfil its tasks under the Act No. 131/2002 Coll. on Universities. Therefore, it must create a system of management that will provide conditions for the proper performance of all necessary functions. If this system includes all the processes necessary to achieve compliance with the requirement of "evaluators" and document the processes in order to prove this capability, this system or the University will be prepared for accreditation, evaluation or certification in accordance with ISO 9001.

This requires:

- integrating the activities associated with the development, registration, distribution and monitoring of publication environment for outputs of $\mathrm{PhD}$ candidates (and other researchers),

- knowledge formulated for continuous quality assessment of publication outputs for the formulation of management strategies of recurring processes of the organization.

\section{Conclusion}

Monitoring and searching for publication space for doctoral candidates is one of the priority tasks of information management of supportive departments of the Faculty (Academic Library, Publishing House) in support of publicising the results achieved by scientific research. Of course, by creating a domestic space, the opportunity of transfer of these results (does not reach the top international quality) is provided, but the aim is particularly to find a 
reputable foreign space for scientific publication outputs. This activity is consistent with the conceptual plan for the development the Faculty. The benefits of economic value can be measured or estimated only by a relatively complex system. There can be expected a quantification increase in income subsidy from achieving the publication outputs in top international quality, the increase in grant success, the enlarged interest of students in postgraduate study based on the selection criteria in their decision of the curricular field. On the other hand, there are benefits characterized by:

- new foreign publications space for MTF STU in renowned foreign publishers,

- strengthening of category "top international quality",

- possible co-authorship with foreign partners and the possibility of comparative scientific works,

- possibility of an increased proportion of citations of authors from MTF STU.

\section{References}

[1] Act No. 131/2002 Coll. on Universities and amending some acts, from http://www.mtf.stuba.sk/english/students/phd.-study.html?pa ge_id $=7775$.

[2] L.C. Amo, S. Ada, and R. Sharman, "The Role of Scholar Status in the Academic Publication," Process. International Journal of Doctoral Studies, 7, 2012, pp. 79-92.

[3] Annual Report 2012, from http://www.mtf.stuba.sk/english/on-faculty/annual-report.ht ml?page_id $=3650$

[4] Dean's Regulation Number 4/2012 Rules for publishing of doctoral students at the MTF STU, from http://www.mtf.stuba.sk/english/students/phd.-study.html?pa ge_id $=777$ 